Article

\title{
Hazy Boundaries: Virtual Communities and Research Ethics
}

\author{
Helena Kantanen ${ }^{1, *}$ and Jyri Manninen ${ }^{2}$ \\ ${ }^{1}$ Business School, University of Eastern Finland, 70211 Kuopio, Finland; E-Mail: helena.kantanen@uef.fi \\ ${ }^{2}$ School of Educational Sciences and Psychology, University of Eastern Finland, 80101 Joensuu, Finland; \\ E-Mail: jyri.manninen@uef.fi \\ * Corresponding author
}

Submitted: 30 January 2016 | Accepted: 19 April 2016 | Published: 10 October 2016

\begin{abstract}
This paper examines ethical issues specific to research into virtual communities. Drawing on an empirical case with online forums of education experts, we identify the following key issues: publicity versus privacy of the community; the definition of human subjects research; participant recruitment; informed consent; and ethical questions associated with observing virtual communities, and with reporting and disseminating research results. We maintain that different research cultures in different countries can present challenges when studying global forums. Acknowledging the ephemeral characteristics of Internet contexts, this paper argues that ethical considerations should be more casebased, instead of relying on one model for all solutions. We suggest that local ethics committees or institutional review boards could, with their expert knowledge of ethics, provide valuable support for researchers operating in the complex and dynamic terrain of Internet research, as well as in fields and research settings where an ethical review is not a standard part of the research process.
\end{abstract}

\section{Keywords}

digital ethics; ethics; ethics committee; institutional review board; Internet research ethics; netnography; online communities; virtual communities

\section{Issue}

This article is part of the issue "Successes and Failures in Studying Social Media: Issues of Methods and Ethics", edited by Epp Lauk and Niina Sormanen (University of Jyväskylä, Finland).

(C) 2016 by the authors; licensee Cogitatio (Lisbon, Portugal). This article is licensed under a Creative Commons Attribution 4.0 International License (CC BY).

\section{Introduction}

The ever-increasing popularity of social media platforms has made them alluring from the point of view of academic research. Researchers now have a unique and cost-efficient opportunity to examine and understand behaviours and beliefs in naturalistic contexts, and to reach populations which may be hard to reach otherwise (Madge, 2007; Moreno, Goniou, \& Moreno, 2013). At the same time, the easy availability of research data made possible by social media raises new ethical questions such as what is public and what is private. Moreover, the prevailing ethical guidelines may not be applicable in all research settings. Therefore, the basic principles of ethical research conduct associated with respecting the autonomy of research sub- jects, avoiding harm, and protecting privacy and data, are extremely topical, and more discussion and understanding is needed about their implications in the context of relatively new electronic environments (Bruckman, 2006; Dennen, 2012; Finnish Advisory Board on Research Integrity, 2009; Hine, 2000; Kozinets, 2010; Markham \& Buchanan, 2012; Zimmer, 2010).

This paper, written from the Finnish perspective, focuses on ethical issues related to the study of discussions on Internet forums-or, more specifically, virtual communities. Virtual communities, or online communities, are Internet-based communication forums or social networks where interaction is based on computermediated communication (Lakkala, 2010; Manninen \& Nevgi, 2000). In these communities, participants typically have a common interest, like product develop- 
ment or the use of social media tools at work (Kosonen, 2009; Wasko \& Faraj, 2005). These communities are also characterised by "public discussions long enough, with sufficient human feeling, to form webs of personal relationships in cyberspace" (Rheingold, 1993, p. 193).

During our ongoing research project (Kantanen, Manninen \& Kontkanen, 2014), we have explored learning, communication and innovation generation, in both a national and global online community. During the different phases of our project, we have tackled several ethical issues. The questions we have asked have included, for example: Do we need an official ethical review when studying a global Linkedln community, administered from the United States? Are we studying a public or private forum? Are community postings exempt? Does our study qualify as human subjects research? What would be an appropriate way to recruit research participants? How would we gain informed consent, and is it always necessary? How should we behave in an online forum when observing participants? How can we safeguard the confidentiality of participants' contributions when reporting the study?

Ethical questions are complicated in the real world but they are even more complex in the virtual environment. Such questions are related to the concepts of public and private, confidentiality, the integrity of data, reputational risks, intellectual property issues, and whether the research qualifies as human subjects research or not. Other issues include participant recruitment, disclosure of presence, and citing, anonymising and crediting when reporting and disseminating research results (Bassett \& O'Riordan, 2002; Bruckman, 2006; Buchanan \& Zimmer, 2013; Hine, 2000; Kozinets, 2010; Markham \& Buchanan, 2012; Turtiainen \& Östman, 2013; Walther, 2002).

The remainder of this paper is organised as follows: Section 2 clarifies different ethical questions concerning Internet research. Section 3 describes our study, the empirical case, and the ethical issues involved with it. Section 4 discusses these issues, and our conclusions follow in Section 5.

\section{Internet Research Ethics}

The Finnish Advisory Board on Research Integrity (2009) defines the ethical principles of research in the humanities and social and behavioural sciences in three regards: (1) respecting the autonomy of research subjects; (2) avoiding harm; and (3) privacy and data protection. Respecting the autonomy of research subjects means, before all, voluntary participation based on informed consent. Harm can be mental, financial or social, and can occur during the collecting of data, retaining of data, or during the publishing of research results. Privacy and data protection involve issues related to protecting research data and confidentiality, storing and destroying data, and publishing research results.
The Advisory Board guidelines emphasise a balance between confidentiality and the openness of research.

Rosenberg (2010) shows how boundary work has challenged Internet researchers and revitalised the discussion about research ethics. For example, boundaries between private and public are often blurred. Rosenberg summarises the general principles of ethical matters: researchers should maximise benefits and minimise harm, people must be treated fairly and equally, research subjects should be treated as autonomous individuals, and those with diminished autonomy must be entitled to protection (Rosenberg, 2010).

One of the key issues in Internet research is whether to use the Internet as a practical research tool (e.g., online questionnaires, Internet-mediated research or online research practice), as a research data source (i.e., studies in the web), or as a research object (i.e., studies about the web) (Turtiainen \& Östman, 2013). Turtiainen and Östman (2013) remind us that, often, all of these elements create a research environment that requires, for example, awareness of source criticisms, knowledge of cultural practices associated with the specific research environment, knowledge about how the data has been created, and an understanding of how research subjects perceive the publicity or privacy of their web presence.

Specific ethical questions related to virtual environments have become topical since 2000 (Turtiainen \& Östman, 2013). Madge (2007) identifies five key issues discussed in the literature on online research ethics: informed consent, confidentiality, privacy, debriefing and netiquette. All of these issues will be discussed later from the point of view of our study. By netiquette, Madge refers to the often flexible codes of conduct or guidelines applied in Internet communication, including phenomena like flaming and online harassment. Tavani (2006) discusses ethical issues related to the increasing use of cybertechnology, which refers to a wide range of computing and communication systems. He calls for cyberethics as "a field of applied ethics that examines moral, legal, and social issues involving cybertechnology" (p. 19). According to Tavani, professional codes of conduct can often help to resolve professional ethics issues, which is also what the different ethical guidelines are meant for. To our knowledge, the most advanced recommendations and guidelines concerning Internet research come from the Association of Internet Researchers (AoIR) and its Ethics Working Committee. They outline general principles that are meant to guide decision-making in Internet research, regardless of rapidly changing technological contexts (Markham \& Buchanan, 2012). Markham and Buchanan call for guidelines rather than a code of practice to ensure the flexibility of research and the usefulness of those guidelines in different research contexts. The major issues or considerations identified in the AolR guidelines are: (1) questions of human subjects research; (2) publicity and privacy; (3) are we studying 
text or persons; and (4) top-down versus bottom-up approaches to ethics (Markham \& Buchanan, 2012). Regarding the last tension, Markham and Buchanan refer to the need for researchers to balance between contextual, case-based requirements, and disciplinary, institutional, legal and cultural constraints.

McKee and Porter (2009a) developed an inquiry strategy to guide decisions about research ethics. They "believe that ethical decision-making for research must be systematic, deliberative, collaborative, and multidisciplinary in order to be valid" (p. 7), and offer a framework for those criteria. According to them, researchers must recognise the special circumstances of each case and be able to situate their case in proximity to other parallel cases and to community expectations in particular (McKee \& Porter, 2009a). Instead of codes of practice or guidelines, they emphasise case-based processes that would help researchers with their decisionmaking in the ever-changing Internet environment (McKee \& Porter, 2009b).

Ethnographic research has an interest in cultures and cultural meanings with an emphasis on the insider view, as well as in language and rhetoric (Eriksson \& Kovalainen, 2016). Robert V. Kozinets coined the concept of netnography, which refers to ethnography conducted online. According to Kozinets (2010, p. 60): "Netnography is participant-observational research based in online fieldwork. It uses computer-mediated communications as a source of data to arrive at the ethnographic understanding and representation of a culture or communal phenomenon."

Kozinets (2010) maintains that "pure" ethnography studies communities or cultures, without important online elements, through face-to-face interaction and data collection, while "pure" netnography does the same, without important in-person elements, through entirely online interaction and data collection. Therefore, Kozinets challenges another pioneer of virtual ethnography, Christine Hine (2000, 2005), who maintains that online ethnography is always partial because the online experience is only one aspect of the social experience, and also because the culture or community studied does not have the field site needed for a holistic description of the culture.
The nature of our study in relation to netnography is examined further in the following section.

\section{The Empirical Case and Its Ethical Challenges}

In our project, our aim is to analyse learning, communication and innovation generation in virtual communities. Our data is derived from discussion threads published in online forums, as explained in Table 1.

In our pilot study (Kantanen et al., 2014), we examined a Finnish web-based community intended for those interested in using social media tools in teaching and learning (Sometu; http://sometu.ning.com). As of September 2013, that community, Sometu, had 4,828 members. The research question in our pilot study was: What are the prerequisites of learning and innovation development in virtual communities of practice used by professionals? In the more recent study (Kantanen \& Manninen, 2014), the empirical data were collected from the international LinkedIn group Higher Education Teaching and Learning (HETL), founded in February 2010. As of January 2016, the group has 63,124 members. The HETL Linkedln group is a network of professionals who participate by using their own names, job titles and photos. The research question of this study is: How can discussions in virtual communities contribute to professional learning and development? In addition to these studies, our project included Master's theses writers who use the HETL discussion threads as data. One completed thesis analysed the sense-making process in a discussion thread concerning the use of electronic devices in class (Tiiliharju, 2015).

This paper focuses on the ethical issues related to our HETL Linkedln group study because its global nature allows more diverse ethical issues to be discussed than national forums. In 2010, at the advent of social media expansion, there was an exciting discussion thread in the HETL LinkedIn community. The opening question was: “Do you accept your students' invitations to connect on Facebook and other social networks?" The discussion continued over seven months and included about 280 discussants from over 190 organisations. Altogether, there were 508 replies. When printed out, the data were 135 pages long. We are interested in

Table 1. Virtual communities of practice project.

\begin{tabular}{|c|c|c|c|c|}
\hline & Online Community & Practitioners Studied & Data & Approach/Methods \\
\hline Pilot study & $\begin{array}{l}\text { Finnish community Social } \\
\text { Media Supporting Web- } \\
\text { Learning (Sometu) }\end{array}$ & $\begin{array}{l}\text { Higher education and } \\
\text { business experts involved } \\
\text { in the use of social media } \\
\text { in education }\end{array}$ & $\begin{array}{l}\text { Discussion } \\
\text { threads }\end{array}$ & $\begin{array}{l}\text { Qualitative content } \\
\text { analysis (ATLAS.ti) }\end{array}$ \\
\hline Current study & $\begin{array}{l}\text { Global Linkedln } \\
\text { community, Higher } \\
\text { Education Teaching and } \\
\text { Learning (HETL) }\end{array}$ & $\begin{array}{l}\text { Higher education and } \\
\text { business experts involved } \\
\text { in higher education and } \\
\text { learning }\end{array}$ & $\begin{array}{l}\text { Discussion } \\
\text { threads, } \\
\text { online } \\
\text { observations, } \\
\text { interviews }\end{array}$ & $\begin{array}{l}\text { Qualitative content } \\
\text { analysis (ATLAS.ti), } \\
\text { Virtual ethnography } \\
\text { (netnography) }\end{array}$ \\
\hline
\end{tabular}


both the process and the content of idea and innovation development in the forum. We have already studied how new ideas and innovations are developed on virtual forums, and what kinds of ideas and innovations are developed. In this paper, the focus is not on our research results, but on different ethical issues related to the study of this global virtual community of education experts.

Our study qualifies as Internet research because we utilise the Internet to collect data, study how people use the Internet through observing participation in virtual forums, utilise datasets available via the Internet, and employ content analysis to study the web (Markham \& Buchanan, 2012). Drawing on Kozinets (2010), we can consider our study a netnography because we enter discussion forums as researchers, use discussion threads as natural data, observe participants on the forum, and also participate in the discussions ourselves. We are both members of the HETL group, and one of us also participated in the Facebook friending discussion thread. According to Kozinets (2010), netnographers should spend significant time interacting within and becoming a part of an online community. We see this participation as an advantage in our attempt to understand the innovation development process and communication of the group. Moreover, we claim that our thorough understanding of the context, culture and dynamics of the target forums contributed to the quality of our research because we were able to interpret our data from the point of view of our informants (Turtiainen \& Östman, 2013).

\subsection{Challenge 1: Ethical Review}

We completed our literature review on virtual communities in early 2013 (Kantanen et al., 2014) and were ready to proceed to the data collection phase of our study. We thought that it would be a good idea to have the Committee on Research Ethics (equivalent to institutional review boards, or IRBs, in the U.S.) of our home university evaluate and approve our research plan. In our country, and in the field of the humanities and social and behavioural sciences, an ethical review is needed if the study involves an intervention in the physical integrity of subjects, deviates from the principle of informed consent, involves children under the age of 15 , exposes research subjects to strong stimuli and evaluating possible harm requires expertise, has the potential to cause long-term mental harm, or poses a safety risk to subjects (Finnish Advisory Board on Research Integrity, 2009). None of these elements were involved in our planned project; however, we intended to study the global LinkedIn forum, HETL, operated from within the United States, and concluded that obtaining ethical approval would be advisable. The Chair of the Committee assured us that our national procedure is very cautious, and that the evaluation of ethical aspects of the research plan would be valid anywhere in the world.

Neither of us had previous experience with ethical reviews because, in our fields of business and adult education, the standard research process does not include ethical reviews-as it often does, for example, in the field of health research. Moreover, Finland has often been characterised as a high-trust society (e.g., Korhonen \& Seppälä, 2005), which includes trust towards institutions, such as universities and their researchers. Therefore, many research environments have been accessible to our researchers without complicated application procedures.

Our first application was returned for revision, as was the second application. At this stage, however, we had come far enough that no Committee meeting was needed; but we nonetheless had to make final changes, which would then be evaluated and accepted-or rejected-by the Chair and the Secretary. In total, the process from the first application to the supporting statement took 1.5 years. There were several reasons for the delay. First, the instructions given and the structure and themes of the application form were poorly applicable to the type of Internet research we were planning. For this reason, we found it difficult to answer the questions as specifically as was required. Moreover, we were quite frustrated and not able to rewrite the application because of other duties. It was, indeed, very difficult to make decisions about possible ethical issues in advance of our study (Markham \& Buchanan, 2012).

The HETL forum founder, who is the central gatekeeper when accessing the forum, accepted the ethical review from our home university, but it was a long process to gain the ethical approval. We obviously applied for the ethical review without fully thinking through the different aspects of Internet research ethics. Had we known then what we know now, our application would have been accepted in the first round. Our struggle with the ethics committee triggered a more profound understanding of the different and often complex dimensions of Internet research ethics. Because we have realised that both our students and fellow researchers sometimes have quite a nonchalant attitude towards ethical issues and Internet data, we wish to share what we have learned.

\subsection{Challenge 2: Public or Private Forum}

Like many other social media researchers, we pondered whether the HETL LinkedIn group was a public or private forum, or if it was a text more than it was a place. If it was a place, was it a public place? If it was a text, could it be quoted like a book? Or, could it be treated like the Letters to the Editor section in newspapers, where readers submit their input knowing that it will be made publicly available to all readers? 
If the discussions can be considered a text, then the focus is totally different from the point of view of ethics than when dealing with human subjects. Could we observe LinkedIn discussants just as we would observe people in a public place? Or could we consider their inputs in the forum as texts? Does it make a difference if the discussion thread studied is several years old, as compared to a synchronous discussion?

McKee and Porter (2009b) make a distinction between a space and a place. If an Internet site is seen as a space, it is primarily a medium of publication, and the focus of research is mainly on what is published. If it is a place, people gather there to discuss and to share, and the focus of research is on people instead. The dominant view has long been that the Internet is a social domain, and this has led to "an imperative to apply restrictions from the human subjects model" (Bassett \& O'Riordan, 2002, p. 234). The Internet is neither public nor private. It is neither a place (residence) nor a space (publication medium). As Kozinets (2010) explains, it is actually many types of social interaction, including chats, blogs, soundclips, and videos.

Private information is such that an individual can expect it to not be monitored or collected, or made publicly available. However, questions of publicity and privacy are complicated in virtual environments. Even on public forums, people may have expectations of privacy, or find it inappropriate that their inputs are read, collected or analysed by external parties (Dennen, 2012; Markham \& Buchanan, 2012; Walther, 2002; Zimmer, 2010). Even with postings on public discussion forums, people do not expect that their inputs will be analysed. For example, in a public virtual world like Second Life, users consider their virtual homes to be private (Rosenberg, 2010). Also, public blogs have been considered to be a part of their writers' identity and should not be treated as publicly available data (Dennen, 2012; Markham \& Buchanan, 2012). Dennen (2012) maintains that the only reliable way to evaluate a research subject's desire for privacy is to request his or her consent to participate in research.

In our case, our data, the Facebook friending thread in the HETL LinkedIn forum, can be considered as text because it was active several years earlier and is, therefore, archived material. Moreover, the question of publicity was clarified in the HETL Policy, which was published after we started our project. The Policy states that "The HETL Linkedln discussion forum (i.e., global online community or practice) is considered a quasi-public group for the purpose of academic research and existing postings are therefore exempt. However, researchers must get approval from the HETL IRB before starting any research project involving this discussion forum data" (https://www.hetl.org/hetlresearch/). The Institutional Review Board (IRB) was founded after we started our study, but the use of forum postings was approved by the HETL forum's founder, Dr. Patrick Blessinger, and we have committed to keeping him, as well as the Chair of the HETL Review Board, informed about the different phases of our project.

\subsection{Challenge 3: Human Subjects Research-Or Not?}

The definition of human subjects research matters because in many countries, like in the U.S., approval by the Institutional Review Board (IRB) is always required when researching human subjects (Bruckman, 2006). A study becomes human subjects research when the researcher deals and interacts with a living person (Bruckman, 2002). But do we interact with living persons when studying the Linkedln group discussion threads?

"Human subjects research is research in which there is an intervention or interaction with another person for the purpose of gathering information, or in which information is recorded by a researcher in such a way that a person can be identified through it directly or indirectly" (U.S. Department of Health \& Human Services, 2009).

The concept of human subjects research, which was originally related to the treatment of persons in medical experiments, still defines ethical research considerations (Markham \& Buchanan, 2012). The concept has also been criticised by, for example, Bassett and O'Riordan (2002, p. 244), who claim that "research that positions the Internet as a social space containing cultural activity ripe for observation ignores the range of textual applications that the Internet supports." Bruckman (2002) suggests that, instead of human subjects, we should talk about "amateur artists" who use the Internet as a playground to create semi-published work.

According to the definition above, ethnographic Internet research (netnography) is human subjects research. However, research use of spontaneous conversations, gathered in a publicly accessible venue, is not human subjects research, according to the Code of Federal Regulations (2009) that governs Institutional Review Boards (IRBs) in the United States (Kozinets, 2010). The Association of Internet Researchers reminds us that because there are individual persons involved in digital information, researchers might need to consider principles related to research on human subjects (Markham \& Buchanan, 2012).

Terms such as harmful, vulnerable, or personally identifiable information may be more relevant than the human subjects model, at least outside of the regulatory framework of research ethics (Markham \& Buchanan, 2012). Instead of the spatial models behind the human subjects view, Bassett and O'Riordan (2002) suggest a hybrid model of relational ethics that would incorporate text, space and bodies and thus extend the limited application of the human subjects model. They 
argue that the human subjects research model is too narrow and does not consider the Internet as a cultural production of texts.

The conclusion is that research of publicly accessible conversations-or even semi-public conversations, like in our HETL case-is not human subjects research, but this does not exclude the need to consider ethical principles of avoiding harm and protecting privacy.

\subsection{Challenge 4: Participant Recruitment and Informed Consent}

When we discuss recruiting participants for research, we address two separate issues: first, under which conditions can we use the HETL discussions as research material; and second, what kind of process should be applied when recruiting HETL members for additional interviews.

In our study, we have thus far only been dealing with forum discussions. Because the HETL policy considers group postings exempt for academic research, we have not yet been involved in participant recruitment when studying forum postings. Also, Kozinets (2010) states that a netnographer's normal, asynchronous actions in online communities do not require informed consent. However, we are aware that there are different points of view about this. In the U.S., a utilitarian stance may prevail, meaning that benefits to society are weighed against potential risks; whereas in Central and Northern Europe, a deontological or communitarian stance that does not compromise confidentiality and anonymity may be taken (Markham, 2006, p. 48). Despite our Finnish background, we have adopted the Anglo-American view because the focal group for our study is an online forum administrated from the U.S.

The question of informed consent will become relevant at the next stage of our project because informed consent is always required for interviews. Also, the HETL Policy states that when collecting research data directly from research participants, researchers must first get approval from the HETL Institutional Review Board and receive informed consent from the research participants (https://www.hetl.org/hetl-research/). In the ethical review that we went through, the consent form that we made on the basis of Kozinets (2010, p. 194), as well as the process of electronic consent, was approved for our research purposes by our local ethics committee.

Enrolling research participants requires contact between the researchers and the study participants. Several sources consider informed consent to be a cornerstone of ethical research conduct (e.g., Buchanan \& Zimmer, 2013). The process of informed consent involves the participants becoming aware, through conversations, of the purpose of the study, what rights and responsibilities participation involves, the risks and benefits of the study, possible compensation or costs, confidentiality and participant rights (Flicker, Haans, \& Skinner, 2004; Kozinets, 2010). When studying virtual communities, all of this can be done online, and several authors advise gathering all relevant research information into a project website, and obtaining informed consent through a registration page (Bruckman, 2002, 2006; Kozinets, 2010). This process is recommended for adults and non-vulnerable populations, as well as when the research is not high risk.

According to our experience, online groups' Terms of Service and policies are very helpful when pondering the question of participant recruitment (see also Markham \& Buchanan, 2012, p. 8). In our case, the HETL Policy requires HETL Institutional Review Board approval for any research project, as well as informed consent when collecting data directly from forum participants. The Policy also helped shape the publicprivate division and text-space discussion. Moreover, we advise researchers to identify different gatekeepers and to discuss their intentions openly with forum founders, administrators and group moderators. This is what we did with both our national and global group. Then, a statement can be added to the informed consent form that specifies that the study plan has been accepted by the forum administrator or owner.

One could also consider the timing of informed consent from a different point of view. Several authors (Markham \& Buchanan, 2012; McKee \& Porter, 2009b) suggest a process approach to research ethics. One may not need consent when collecting the data, but rather at the reporting and dissemination stage, if one wishes, for example, to quote a forum participant (Dennen, 2012). Many decisions at this stage pose ethical concerns; for example, which (if any) details to reveal about the study site and participants.

\subsection{Challenge 5: Observing the Community}

Much debate exists concerning how researchers should behave when observing a virtual community. The general rule should be to work as transparently as possible because, as Rutter and Smith (2005, p. 90) argue: "the ramifications of unethical disclosure are real and inescapable." However, not even the question of disclosing your presence is simple in the online environment. In our case, it was easy because we did not study synchronous discussions of the HETL LinkedIn group, but rather those that had become active several years earlier, and were already archived. However, during potential new phases of our study, these questions may become more important. We now have enough knowledge to face these questions in an ethical manner; that is, by disclosing our presence as researchers to the forum participants or to the discussants of a specific thread.

Kozinets (2010) advises netnographers to always disclose their presence, affiliations and intentions. Sev- 
eral authors are unequivocal about identity deception, such as Kozinets (2010): "Netnographers should never, under any circumstances, engage in identity deception" (p. 147). Identity deception may occur on the sites studied, but researchers should always identify themselves. There are different ways to do this, such as putting information about ongoing research on one's own personal profile (Bruckman, 2006).

There may be projects that would be unsuccessful if the researcher were to disclose his or her presence. Hudson and Bruckman (2004) studied how chatroom discussants responded to the researchers' presence and/or attendance in their forum and found that they reacted with hostility when they became aware of being studied. Therefore, the researchers considered the informed consent process to be impracticable. Sanders (2005) observed online communities of sex workers without disclosing her presence, as a so-called "lurker". She did not want the participants to alter their behaviour, nor did she want to harm the shared community or provoke hostility. Sometimes, this kind of anonymity may also protect the researcher. There may be some unwanted consequences if the researcher were to reveal his or her identity and affiliations to certain online groups (Sanders, 2005). It is possible that because hostile online behaviour is becoming more common (Jane, 2015), researchers might need to consider their own protection, even when studying relatively "safe" online forums-especially if discussed issues are sensitive, such as topical discussions revolving around asylum seekers. Bruckman (2006) gave an example of a student researcher who became the victim of racism on the site that he was studying. We know from our home university that hostile messages have been targeted at researchers working on issues related to immigration (Mikkonen, 2015).

\subsection{Challenge 6: Reporting and Dissemination}

Reporting and dissemination ethics apply to the various media in and through which research results are presented: academic journals and reports, conference presentations, websites, videos, press releases, interviews and information leaflets. Each of these reporting and dissemination mediums have their own distinct consequences. For example, writing about research methods transparently and in detail increases the credibility of a study.

It is obvious that there has been a delay in our research publication and reporting efforts because of the different ethical concerns we have experienced. The ethical questions at this phase of the study include, in our experience, questions of citing, anonymising, and crediting. Can we mention the HETL LinkedIn group and the specific discussion thread studied in our articles? Do the participants own copyright over their input in the discussion forum? If so, do we need to add author references for all cited input? And, if we delete all identifiers (like names and affiliations) to protect the informants' privacy, how do we give credit to those who contributed innovative ideas in the discussion thread?

Bruckman (2006, p. 91) states that "one of the thorniest problems concerns how to disguise names of people and sites." She asks how the researcher should balance the need to protect research participants with the need to give credit for their work (Bruckman, 2002). She uses the metaphor of "amateur artists", meaning that "all user-generated content on the Internet can be viewed as various forms of amateur art and authorship" (p. 229); consequently, these amateur artists deserve credit for what they have produced.

Bruckman (2002) proposes different levels of disguising, on a continuum from no disguise, to light and moderate disguise, to heavy disguise. In the case of no disguise, the report would have real names or pseudonyms of research subjects and the researcher would, therefore, respect the individual's copyright over his or her input. At the other end of the continuum, in the case of heavy disguise, the group studied would not be named and all identifying details would be changed. The report would include no verbatim quotes, and some false details might be introduced. It is worth noting that one cannot be careful enough with personal data. Zimmer (2010) explains a case where the researchers failed to anonymise their data with information about 1,700 college students' Facebook profiles. Even though all of the identifiers were deleted or encoded, the university in question was discovered and the privacy of research subjects' sensitive personal information was endangered.

Our case falls into the category of "light disguise" (Bruckman, 2002), where the community studied is named but participant names and some other identifying details like organisational affiliations are removed. We are also going to use verbatim quotes in our papers, even if they can be used to identify a group member with the help of search engines. For example, Moreno et al. (2013) advise against direct quotations to protect confidentiality. We do not consider this to be a problem because, as explained above, our study is not of high risk and, therefore, light disguise should be enough. Some authors have adopted the utilitarian approach to research ethics (Markham, 2006). For instance, Bruckman (2002) advises balancing the degree of risk against the benefits of the study, while Markham and Buchanan (2012) advise balancing the rights of subjects with the social benefits of the research and researchers' rights to conduct research.

McKee and Porter (2009b, p. 88) illustrate this issue of disguising by constructing a figure within which the necessity of informed consent can be assessed according to the following variables: Public vs. private, Topic sensitivity, Degree of interaction and Subject vulnerability. Each variable should be evaluated along the pri- 
vate-public or high-low scale. At the "low end" of the scale, consent may not be necessary; while at the "high end" of the scale, consent will most likely be required. The authors emphasise that these variables can be hard to determine and can also be culture-specific; in other words, a sensitive topic for one culture may not be sensitive at all for another. That said, our study occupies the "low end" of the scale in regards to all of these variables.

Importantly, our research question specifically examines verbatim quotes, not who said them, which thus eliminates the need to give credit to discussion participants. The main purpose of our study is neither to analyse what kind of innovations are generated in a discussion nor to examine the behaviour of those who generate them. Instead, the objective is to analyse online discussions and the internal logic of how textbased, delayed, asynchronous communication develops and proceeds in online communities (see Kantanen et al., 2014). In other words, we are not interested in who wrote what; rather, we are interested in the types of input (e.g., questions, experience sharing, reflections, etc.) generated in online discussions, as well as whether such discussions follow the five cycles of value creation (Wenger, Trayner \& de Laat, 2011). As such, in this kind of analysis, verbatim quotes are importanteven mandatory-because the research focus is on how text is written.

Bruckman (2002) suggests that if the study is low risk, the researcher could ask the research subjects if they want a pseudonym, real name, both, or neither to be used. If the study is high risk, it is not appropriate to list names or pseudonyms. Minimal risk means, by definition, "that the probability and magnitude of harm or discomfort anticipated in the research are not greater in and of themselves than those ordinarily encountered in daily life or during the performance of routine physical or psychological examinations or tests" (U.S. Department of Health \& Human Services, 2009, Section 46.102). Our study falls into this category of minimal risk.

Ethical research conduct could and should also include the sharing of research results with the community studied so that corrections in the analysis and interpretation of the results can be made when needed (Madge, 2007). This kind of conduct might contribute to a more positive online environment where the researchers would be met with trust rather than with suspicion. We shared the results of our pilot study (Kantanen et al., 2014) with the national Sometu community and received positive feedback from the forum administrators.

\section{Discussion}

In the following, we discuss our case in light of the basic ethical principles of research defined in our coun- try: respecting the autonomy of research subjects, avoiding harm, and protecting privacy and data (Finnish Advisory Board on Research Integrity, 2009).

Participation in research must be voluntary and based on informed consent. So far, we have not necessarily needed consent because we have been studying archived online discussion threads. When interviewing participants, we will need their consent, which we can gain electronically by using a form accepted by the Committee on Research Ethics of our university. The form includes the following information for the research subjects: project title, research team members, purpose of the study, research funding, information about what participation will involve, risks, benefits, costs and compensations, confidentiality, participant rights, and contact information (see also Kozinets, 2010, p. 194).

Our study has not at any stage included particularly vulnerable groups like minors, cognitively impaired people, survivors of abuse, or support groups for those with serious diseases. Groups of that kind are, of course, very vulnerable and deserve extra protection and careful ethical consideration.

In our country, some exemptions from informed consent are possible "if advance information would distort the results of the study" (Finnish Advisory Board on Research Integrity, 2009, p. 8). For example, power relationships can be studied without the consent of those in power, or there may be groups that can be a risk to the researcher's safety if he or she reveals his or her identity. In these cases, ethical review is always necessary. Research cultures differ from country to country and, therefore, global forums present challenges. For instance, many virtual communities and social media platforms are owned by and administered from the United States; therefore, it is not enough to take national guidelines of research ethics into account, but U.S. standards as well. Moreover, if the research results are to be published in one of the "international" languages, other nations' standards may also need to be taken into account.

We consider the question of protecting Internet researchers a very topical one, even though this has not been a problem in our study. What if a senior investigator sends a junior to study a hostile online forum and the research subjects trace his or her personal information and start verbal attacks with threats of off-line violence? Is this a question of research ethics? Or is it unethical to withdraw from studying risky issues and/or forums because of fear? Both Bruckman (2006) and Jane (2015) give terrifying examples of what impudent online hostility-Jane calls this "e-bile" - can involve. Therefore, we wish to include the aspect of protecting researchers, particularly inexperienced junior researchers, in our ethical considerations.

We have attempted to treat our research subjects with respect and dignity, which is not difficult because 
they (like us) are mostly experts within the field of education. Our study does not include elements that might cause mental, financial or social harm to the research subjects. If, however, we had studied synchronous interaction in online communities, our presence might have had negative consequences to the natural flow of conversations and could have provoked irritation or hostility-mental harm, that is.

The Terms of Service of different virtual platforms may have different views on privacy than those of their users (Markham \& Buchanan, 2012). Moreno, Goniou and Moreno (2013) give examples of cases where courts have concluded that a person cannot expect privacy when posting on social networking sites. Often, ethical demands can be harder than legal ones. Extant laws set the ultimate limits, but do not necessarily determine what is ethical. In this article, our focus has been on ethical, not legal considerations (for a possible basis for legal liability of Internet researchers, see Lipinski, 2006).

Protecting privacy in research publications may be challenging because we use direct quotes from our data. However, as explained above, the issues discussed in our community are not very sensitive; therefore, a "light disguise" (Bruckman, 2002), where the names and other identifiers are hidden, should be enough. It is of course possible that if a quotation appears in a journal article, someone could track the original source of the quotation with the help of a search engine. Therefore, there is a slight risk that our study might cause some reputational harm to forum participants if, for example, original quotations with hostile and aggressive comments, "flames" can be tracked. However, this risk is low and, if we ever publish any flamingrelated quotes, the focus will be on showing how moderators diffuse heated situations in a specific virtual community, not on the identities of those involved in them.

In our project, each researcher is responsible for safeguarding the research materials in his or her office and office computer. For ethical reasons, the materials may not be handed over to third parties-not even after the research project has been finished. After the project, the research data will be stored at the university for ten years according to the prevailing archive's regulations. Our data will not be available for secondary research, not even without identifiers, because this is the procedure accepted by our ethics committee. In this regard, the ethics committee may need to change their view because of increasing demand for openly accessible research data.

\section{Conclusion}

"Internet research ethics is complex, not impossible" (McKee \& Porter, 2009b, p. 141). However, Bruckman (2006) maintains that studying online communities in an ethical fashion is a challenge, even for experienced researchers, and that the Internet continually raises novel ethical issues. If we are too lax in our ethics, we may violate the rights of individuals, or disrupt the communities we study; if we are too strict, we may not gain the knowledge needed to understand these communities (Bruckman, 2002, p. 218). She gives an example of how one student of hers was denied access to study an online group because someone else had studied the community earlier, "and left members feeling like their activities were disrupted and their privacy violated" (Bruckman, 2006, p. 217). Therefore, forgetting ethical conduct harms the whole academia.

Working with international forums can prove problematic. Researchers, forum owners and moderators, and research subjects may come from very different cultures, including research cultures with different views on research ethics. Therefore, we recommend consulting the ethical review board of one's own university. First, it is much easier to approach an international community with ethical approval, because in many countries it is always a part of any research process. Moreover, the process makes researchers seriously consider different ethical aspects of their projects. That said, we would like to add that, of course, it helps if the local ethics committee or review board has a supportive, advisory attitude towards its researcher clients. By delving into the complexities of Internet research, we have also tried to pay attention to the need for ethical considerations in fields where official reviews are not necessary. For us, the process that started with our local ethics committee has been very useful in the long run.

Acknowledging the ephemeral characteristics of Internet contexts, we argue that, in line with other authors (Markham \& Buchanan, 2012; McKee \& Porter, $2009 \mathrm{~b})$, ethical considerations should be more casebased and processual, rather than relying on one model for all solutions. We suggest that local ethics committees or institutional review boards could, with their expert knowledge of ethics, provide valuable support for researchers operating in the complex and dynamic terrain of Internet research, as well as in fields and research settings where an ethical review is not a standard part of the research process. There may also be a need for these review boards to revise their instructions and forms to better respond to the volatile research environments studied by Internet researchers (Dennen, 2012).

\section{Acknowledgements}

This article is one of the fruits of the Innovation Practice Project of the Business School of the University of Eastern Finland, funded as one of the Innovative Research Initiatives of the University during 2011-2014. It originated in a workshop on Ethical and Unethical Re- 
search of Internet Data, held by Helena Kantanen, at the International Doctoral Consortium on Management and Organization Studies at St. Mary's University, Halifax, in June 2014. The key points of this paper were presented at the Social Media Research Symposium at the University of Jyväskylä, Finland, on November 20, 2015. We thank our colleagues, Professor Päivi Eriksson and Professor Albert J. Mills, for their valuable insights on improving the manuscript.

\section{Conflict of Interests}

The authors declare no conflict of interests.

\section{References}

Bassett, E. H., \& O'Riordan, K. (2002). Ethics of Internet research: Contesting the human subjects research model. Ethics and Information Technology, 4(3), 233247.

Bruckman, A. (2002). Studying the amateur artist: A perspective on disguising data collected in human subjects research on the Internet. Ethics and Information Technology, 4(3), 217-231.

Bruckman, A. (2006). Teaching students to study online communities ethically. Journal of Information Ethics, Fall 2006, 82-95.

Buchanan, E., \& Zimmer, M. (2013). Internet research ethics. In E. N. Zalta (Ed.), The Stanford encyclopedia of philosophy (Fall 2013 Edition). Retrieved from http://plato.stanford.edu/archives/fall2013/entries/ ethics-Internet-research

Dennen, V. P. (2012). When public words are not data. Online authorship, consent, and reasonable expectations of privacy. In D. Heider \& A. L. Massarini (Eds.), Digital ethics (pp. 21-38). New York: Peter Lang.

Eriksson, P., \& Kovalainen, A. (2016). Qualitative methods in business research. A practical guide to social research. London: Sage.

Finnish Advisory Board on Research Integrity. (2009). Ethical principles of research in the humanities and social and behavioural sciences and proposals for ethical review. Retrieved from http://www.tenk.fi/ sites/tenk.fi/files/ethicalprinciples.pdf

Flicker, S., Haans, D., \& Skinner, H. (2004). Ethical dilemmas in research on Internet communities. Qualitative Health Research, 14(1), 124-134.

Hine, C. (2000). Virtual ethnography. London: Sage.

Hine, C. (2005). Virtual methods and the sociology of cyber-social-scientific knowledge. In C. Hine (Ed.), Virtual methods. Issues in social research on the Internet (pp. 1-13). Oxford: Berg.

Hudson, J. M., \& Bruckman, A. (2004). "Go away": Participant objections to being studied and the ethics of chatroom research. The Information Society, 20(2), 127-139.

Jane, E. A. (2015). Flaming? What flaming? The pitfalls and potentials of researching online hostility. Ethics and Information Technology, 17(1), 65-87.

Kantanen, H., \& Manninen, J. (August, 2014). Seeds, sprouts, weeds and blooms of innovation: Learning in professional virtual communities. Paper presented at the 7th EARLI SIG 14. Learning and Professional Development Conference. Transformations in Knowledge and Professional Learning, Oslo, Norway.

Kantanen, H., Manninen, J., \& Kontkanen, J. (2014). Emergent dialogue as a prerequisite of learning and innovation in professional virtual communities. International Journal of Web Based Communities, 10(2), 211-231.

Korhonen, J., \& Seppälä, N. (2005). The strength of a high-trust society. In A. Habisch, J. Jonker, M. Wegner, \& R. Schmidpeter (Eds.), Corporate social responsibility across Europe (pp. 13-22). Berlin: Springer.

Kosonen, M. (2009). Knowledge sharing in virtual communities-A review of the empirical research. International Journal of Web Based Communities, 5(2), 144-163.

Kozinets, R. V. (2010). Netnography. Doing ethnographic research online. Los Angeles: Sage.

Lakkala, M. (2010). How to design educational settings to promote collaborative inquiry: Pedagogical infrastructures for technology-enhanced progressive inquiry. (Doctoral dissertation). University of Helsinki, Helsinki, Finland. Retrieved from http://urn.fi/URN: ISBN:978-952-10-6178-3

Lipinski, T. A. (2006). Emerging tort issues in the collection and dissemination of Internet-based research data. Journal of Information Ethics, Fall 2006, 55-81.

Madge, C. (2007). Developing a geographers' agenda for online research ethics. Progress in Human Geography, 31(5), 654-674.

Manninen, J., \& Nevgi, A. (2000). Opetus verkossa [Teaching in the Web]. In J. Matikainen \& J. Manninen (Eds.), Aikuiskoulutus verkossa: Verkkopohjaisten oppimisympäristöjen teoriaa ja käytäntöä. [Adult Education in the Web-Theory and Practice of Web Based Learning Environments] (pp. 93-108). Helsinki: Palmenia-kustannus.

Markham, A. N. (2006). Ethic as method, method as ethic: A case for reflexivity in qualitative ICT research. Journal of Information Ethics, Fall 2006, pp. 37-54.

Markham, A., \& Buchanan, E. (2012). Ethical decisionmaking and Internet research. Recommendations from the AolR ethics working committee (version 2.0). Retrieved from http://aoir.org/reports/ethics 2.pdf

McKee, H. A., \& Porter, J. E. (2009a). Playing a good game: Ethical issues in researching MMOGs and virtual worlds. International Journal of Internet Research Ethics, 2(1), 5-37.

McKee, H. A., \& Porter, J. E. (2009b). The ethics of internet research: A rhetorical, case-based process. New York: Peter Lang. 
Mikkonen, J. (2015, November 7). Tutkija sai tarpeekseen vihapuheesta-harkitsee tutkintapyyntöä [Researcher Fed Up with Hostile MessagesConsiders request for investigation]. Savon Sanomat. Retrieved from http://www.savonsanomat.fi/uuti set/kotimaa/ita-suomen-yliopiston-tutkija-sai-tarpee kseen-vihapuheesta-harkitsee-tutkintapyyntoa/2164 266

Moreno, M. A., Goniou, N., \& Moreno, P. S. (2013). Ethics of social media research: Common concerns and practical considerations. Cyberpsychology, Behavior, and Social Networking, 16(9), 708-713.

Rosenberg, $\AA$. (2010). Virtual world research ethics and the private/public distinction. International Journal of Internet Research Ethics, 3(12), 23-35.

Rutter, J., \& Smith, G. W. H. (2005). Ethnographic presence in a nebulous setting. In C. Hine (Ed.), Virtual methods. Issues in social research on the Internet (pp. 81-92). Oxford: Berg.

Sanders, T. (2005). Researching the online sex work community. In C. Hine (Ed.), Virtual methods. Issues in social research on the Internet (pp. 67-79). Oxford: Berg.

Tavani, H. T. (2006). Cyberethics as an interdisciplinary field of applied ethics. Key concepts, perspectives, and methodological frameworks. Journal of Information Ethics, Fall 2006, 18-36.

Tiiliharju, P. (2015). Yhteisöllinen oppiminen ja järkeistäminen virtuaalisissa käytäntöyhteisöissä [Collective learning and sensemaking in virtual communities of practice] (Master Thesis). University of Eastern Finland, Joensuu, Finland.

Turtiainen, R., \& Östman, S. (2013). Verkkotutkimuksen eettiset haasteet: Armi ja anoreksia [Ethical challenges of internet research: armi and anorexia]. In S. Laaksonen, J. Matikainen, \& M. Tikka (Eds.), Otteita verkosta. Verkon ja sosiaalisen median tutkimusmenetelmät [Grips on the net. Internet and social media research methods] (pp. 49-67). Tampere: Vastapaino.

U.S. Department of Health \& Human Services. (2009). Code of federal regulations. Title 45. Public welfare department of health and human services. Retrieved from http://www.hhs.gov/ohrp/humansubjects/guid ance $/ 45 \mathrm{cfr} 46 . \mathrm{html}$

Walther, J. B. (2002). Research ethics in Internet-enabled research: Human subjects issues and methodological myopia. Ethics and Information Technology, 4(3), 205-216.

Wasko, M. M., \& Faraj, S. (2005). Why should I share? Examining social capital and knowledge contribution in electronic networks of practice. MIS Quarterly, 29(1), 35-57.

Wenger, E., Trayner, B., \& de Laat, M. (2011) Promoting and assessing value creation in communities and networks: A conceptual framework. Retrieved from http://wenger-trayner.com/wp-content/uploads/20 11/12/11-04-Wenger_Trayner_DeLaat_Value_creati on.pdf

Zimmer, M. (2010). "But the data is already public": On the ethics of research in Facebook. Ethics and Information Technology, 12(4), 313-325.

\section{About the Authors}

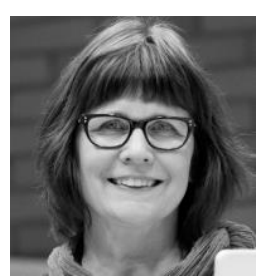

Helena Kantanen (PhD) is a Senior Lecturer with the Innovation Management Team of the Business School of the University of Eastern Finland. She joined the faculty in 2010, after 20 years as a PR practitioner, manager, and consultant. Her research focuses on virtual expert communities and on business renewal through participative management, leadership and communication. Helena's teaching involves courses concerned with marketing, communication and leading and managing change. She is a regular Erasmus visitor of ESTICE Business School, in Lille, France.

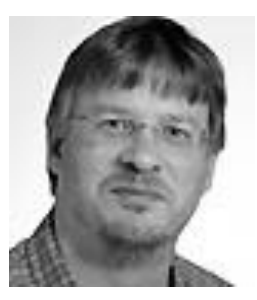

Jyri Manninen (EdD) is a Professor of Adult Education at the University of Eastern Finland. His research interests include adult learning processes and human interaction in various face-to-face and online learning situations. One research topic has been computer-mediated communication in webbased learning environments and emergent dialogue in virtual expert communities. 